Rey Villaronga, Gonzalo José.

Artista visual e investigador. Universidade de Vigo, Facultade de Belas Artes. Estudiante de

Doctorado, Departamento de Pintura.

\title{
El tapado de la imagen como estrategia de producción artística.
}

\section{Covering the image as an artistic production strategy.}

\author{
TIPO DE TRABAJO:
}

Comunicación.

PALABRAS CLAVE

Negación, antivisualidad, tapado, espejo.

KEY WORDS:

Denial, antivisual, covered, mirror.

RESUMEN.

Este artículo analiza la obra "Mirror" de David Hammons, para mostrar como el tapado de la obra de arte continúa siendo una estrategia crítica de antivisualidad frente a la sobre abundancia de imágenes. Éste es un análisis y una interpretación que forma parte de un trabajo más extenso que desarrollamos sobre las prácticas antivisuales en la contemporaneidad.

\section{ABSTRACT.}

This article analyzes the work "Mirror" by David Hammons, to demonstrate how the capping of the work of art continues to be a critical strategy of anti - existentialism against the abundance of images. This is an analysis and an interpretation that is part of a more extensive work that we develop on the anti-traditional practices in the contemporaneity.

\section{CONTENIDO.}

\section{Introducción.}

Siguiendo la investigación de Hernández-Navarro que plantea que existe una estética de la negación [donde] podemos encontrar diferentes posicionamiento de los artistas y diversos resultados en el eje que transcurre de la materialización a la desmaterialización de la obra"(Hernández- Navarro, 2016:18) nos centraremos en la importancia de la ocultación. En el trabajo de David Hammons (U.S.A., 1943) negar la posibilidad de ver y provocar la curiosidad es una de las estrategias que utiliza el artista a través de su obra. Un artista que comenzó burlándose del mercado cuando al principio de su carrera vendía durante el invierno de Harlem bolas de nieve como obras de arte. Comprometido con los derechos civiles, su trabajo reflexiona sobre las experiencias de la vida afroamericana y el papel que juega en la sociedad americana. La serie mirrors (espejos) forma parte de una destacada trayectoria donde performance, pintura, escultura, y toda clase de prácticas artísticas son utilizadas para provocar la curiosidad en el espectador. Frente a la eficacia e inmediatez con la que el sistema del arte y el sistema en general categoriza, digiere y canibaliza los acontecimientos, la negación sostenida se convierte en un valor añadido para sus obras. Sólo hay que pensar en el contexto en el que nos movemos con las políticas de visibilidad, donde las redes de vigilancia se multiplican y los individuos abiertamente nos exponemos al mundo, cualquier muestra de ocultación es tomada como un acto de rebeldía. Negar la posibilidad de ver y provocar la curiosidad es una de las estrategias que utiliza el artista a través de su obra. El trabajo de la última década comenzaba con Concerto in Black and Blue, (2002), (Concierto en azul y negro) en el que el artista invitaba a los espectadores de una galería en el Shoho de Nueva York a visitar el espacio en su 
oscuridad total, únicamente equipados con pequeñas linternas azules para moverse por el espacio. Se le daba así un nuevo giro a la convención de galería vacía que desde el título giraba hacia nuevos significados relacionados con la música, la raza, el color y la violencia.

\section{Mirror, 2012. Espejos.}

"Se ha dicho del espejo que es símbolo de la imaginación o de la conciencia, ya que tiene la capacidad de reproducir los reflejos del mundo visible en su realidad formal. Scheler y otros filósofos lo han relacionado con el pensamiento, pues es en el vehículo mental donde se produce la autocontemplación y reflejo del Universo. Es en este sentido en el que el espejo se relaciona con el simbolismo del agua reflejante y el mito de Narciso". (Ferrer, 2017)

Parecido procedimiento tenía lugar con sus obras Mirror (Espejos) donde en el interior de los barrocos marcos dorados los reflejos eran subvertidos también por telas de arpillera negando al espectador la idea renacentista de representar su propia imagen especular. De estas obras se ha dicho que se trataría de un arte donde los blancos no podía verse así mismos. En realidad su obra logra que nos detengamos y pensemos sobre el arte, nos obliga a solicitar una cita para satisfacer nuestra curiosidad y reflexionemos sobre que es lo que esperamos ver en una obra.

\section{Kool Aids.}

Con sus pinturas ocultas o pinturas de lona, Kool Aid establecía un nuevo diálogo con los medios artísticos tradicionales de la abstracción pero totalmente subversivo. En las obras creaba abstracciones gestuales como un guiño al canon modernista pero luego se nos eran negadas a la visión, cubriendo sus dibujos y pinturas con hojas viejas, lonas de plástico arrugado y arpillería rasgada obtenida de obras en construcción. Sólo en ciertas exhibiciones a partir del 2012, y bajo previa cita entrando por un lugar diferente al del centro de la muestra, los visitantes podían ver las obras con un miembro del personal de la exposición. Eran enigmas premeditados donde la experiencia se convertía en un ritual de desvelamiento de lo prohibido. En estos casos las obras estaban cubiertas por un velo de cruda seda blanca que impedía la tentación de ver lo que asomaba por debajo. El ritual llegaba al extremo de una cartela en la que se indicaba al visitante la dirección de un correo electrónico donde podía pedir cita previa para poder ver la obra. El artista lograba así mantener expectante la mirada del visitante.

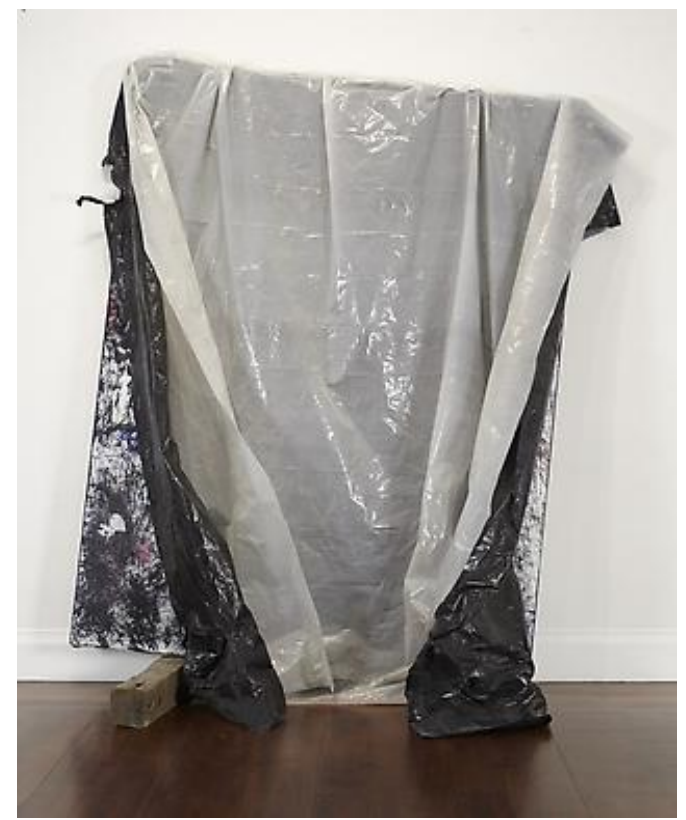

Figura 1. (Sin título) Fotografía de la serie Kool Aids del 2012. 


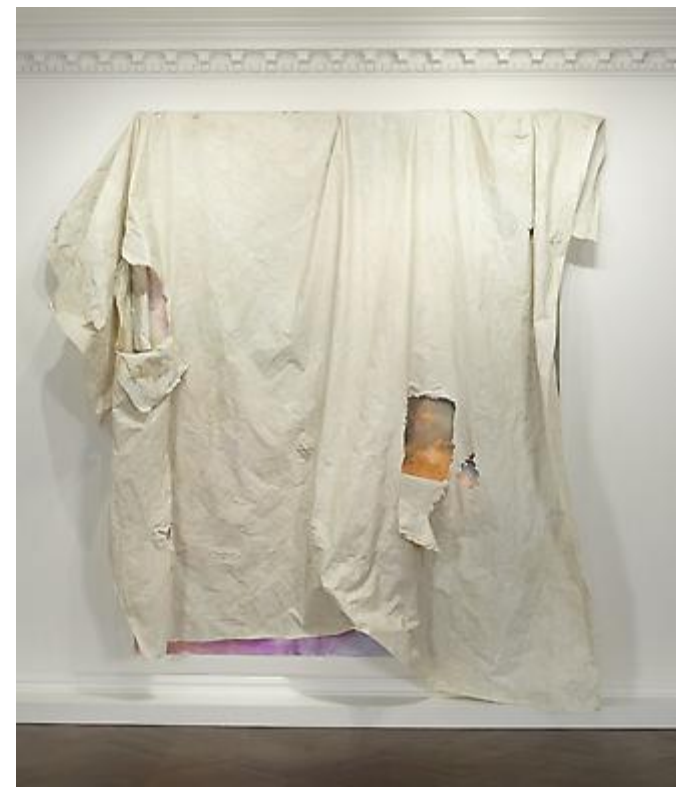

Figura 2. (Sin título) Fotografía de la serie Kool Aids del 2012.

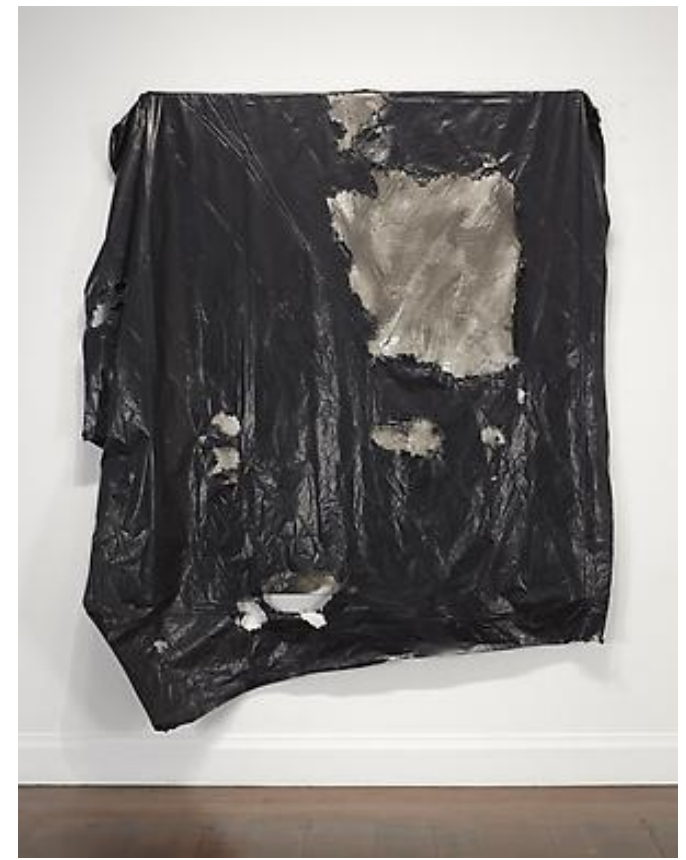

Figura 3. (Sin título) Fotografía de la serie Kool Aids del 2012. 


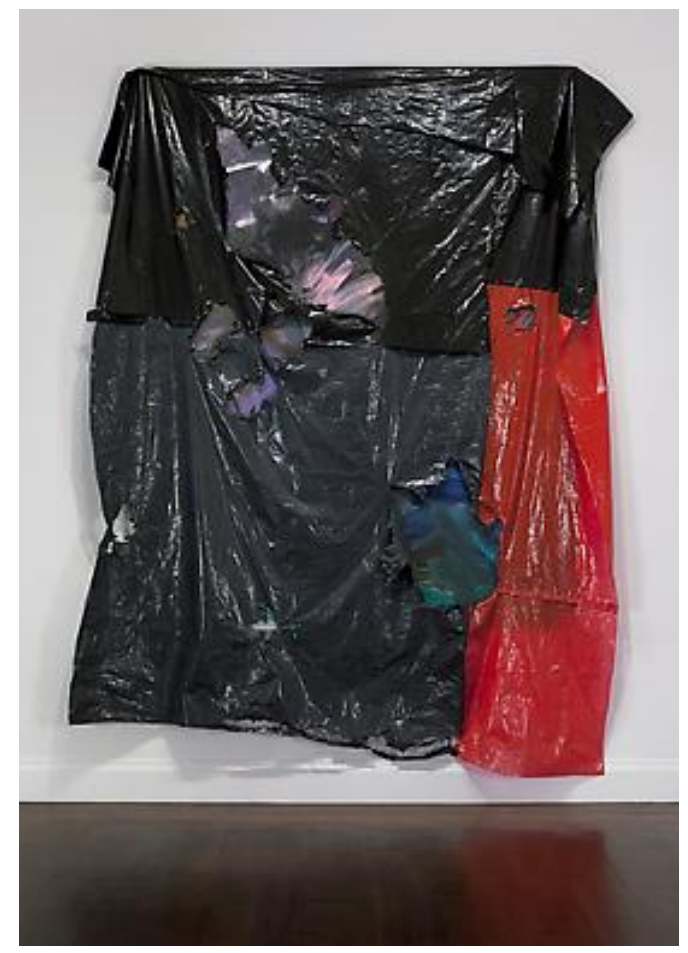

Figura 4. (Sin título) Fotografía de la serie Kool Aids del 2012.

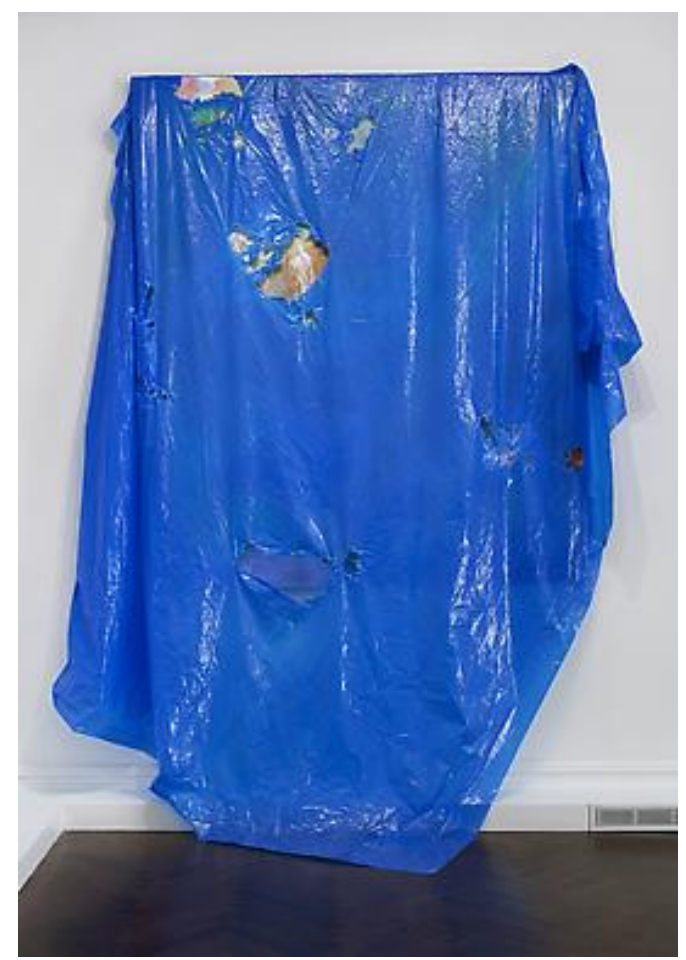

Figura 5. (Sin título) Fotografía de la serie Kool Aids del 2012. 


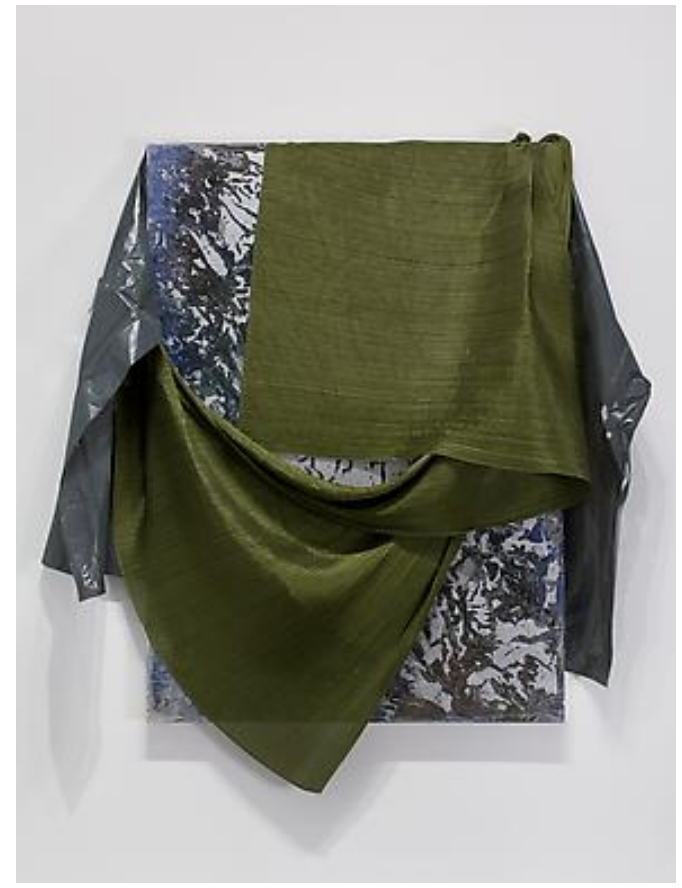

Figura 6. (Sin título) Fotografía de la serie Kool Aids del 2012.

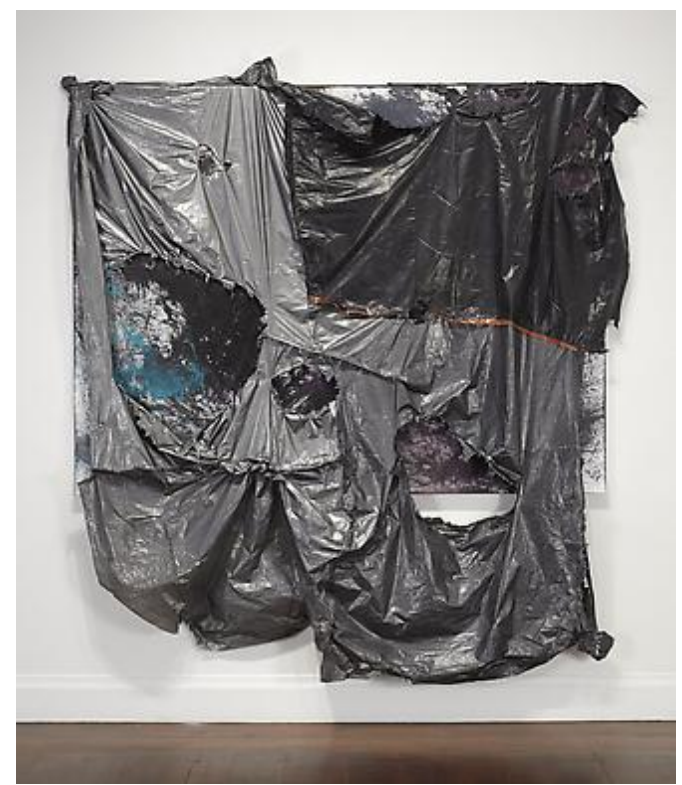

Figura 7. (Sin título) Fotografía de la serie Kool Aids del 2012. 


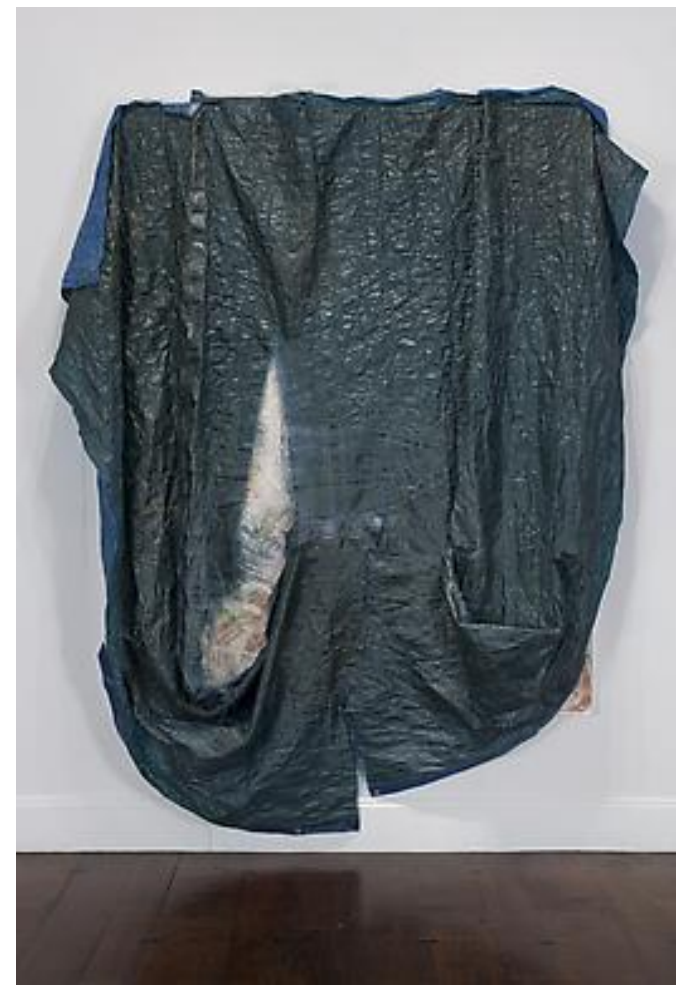

Figura 8. (Sin título) Fotografía de la serie Kool Aids del 2012.

\section{El concepto de tapado retomado.}

Interpretar el concepto de tapado de la imagen heredado de sus pinturas ocultas o pinturas de lona (Kool Aids) nos ayuda a establecer relaciones con otras obras de la antivisualidad y la ocultación como estrategia de cuestionamiento.

\begin{tabular}{|l|l|l|}
\hline \multicolumn{2}{|l|}{ Tapado } & \multicolumn{2}{|l|}{} \\
\hline \multirow{3}{*}{ pp. s. XX } & Pliant ... de voyage (Plegable... de viaje) 1916 & Marcel Duchamp \\
\cline { 2 - 3 } & L'Enigme d'Isidore Ducasse (1920) & Man Ray \\
\hline \multirow{3}{*}{ Años 70 } & Fotografía de Marilyn Monroe (1962) & Christo y Jeanne Claude \\
\cline { 2 - 3 } & Pinturas habitadas (1975) & Helena Almeida \\
\hline \multirow{3}{*}{ Actualidad } & All (2007) & Maurizzio Cattelan \\
\cline { 2 - 3 } & Painting Póster (2007) (Pinturas póster) & Klara Lidén \\
\cline { 2 - 3 } & Family Friendly (2012) & Fayçal Baghriche \\
\hline
\end{tabular}




\section{Rey Villaronga, Gonzalo José \\ El tapado de la imagen como estrategia de producción artística \\ III CONGRESO INTERNACIONAL DE INVESTIGACIÓN EN ARTES VISUALES :: ANIAV 2017 :: GLOCAL [codificar, mediar, transformar, vivir] http://dx.doi.org/10.4995/ANIAV.2017.5843}

En 1916 Marcel Duchamp realizó su ... Pliant ... de voyage (Plegable... de viaje), una simple funda de una máquina de escribir bajo la que no sabemos lo que se encuentra. En la obra especulaba sobre la categoría de lo oculto. Reflexionaba sobre lo que no nos es accesible, lo que se ratifica por su propia ausencia visible y genera, en contrapartida, un fuerte deseo de conocer lo que se nos está vedado, lo oculto. Ésa lectura incide en su filosofía del ready made como máquinas de significar que el espectador tiene que poner en funcionamiento. Inicios de procesos mentales o, en este caso, emocionales. La creación de un deseo oscuro, el juego con los enormes tentáculos del deseo donde la obra se expande a territorios hasta entonces desconocidos para anunciar un secreto del que luego se nos niega su revelación, produciéndose así una potente sensación de intriga y necesidad.

La obra L'Enigme d'Isidore Ducasse (1920) de Man Ray consiste en un objeto envuelto en una manta y atado con una cuerda. Esta escultura enigmática, esta obra velada (Reguera,2008), tapa un objeto oculto cuyo encubrimiento sugiere una presencia irreal. Para el artista, como para muchos dadaístas y surrealistas, el título era una estrategia para desencadenar un imaginario no racional basado en el azar y como puede ser este caso, a menudo con cierto simbolismo sexual encubierto. La escultura, una máquina de coser cubierta en realidad, encapsula la visión de lo que podemos ver. Estos temas, vinculados al atado y a la ocultación, los podemos ver también en Christo aunque a diferencia de las obras de éste, la obra de Man Ray siempre mantenía el misterio de lo ocultado. Una fotografía de la versión original de la obra se reprodujo en uno de los números de la revista La Révolution Surréaliste en diciembre de 1924 y el texto que la acompañaba era un manifiesto donde se declaraba la importancia de los sueños en el surrealismo. En consecuencia, la fotografía de este misterioso objeto había sido seleccionada para imposibilitar la visión de lo que había más allá de la aprehensión racional y de las normas de la realidad diaria de los surrealistas.

Mencionando a Christo y Jeanne Claude a finales de los años cincuenta la pareja de artistas comenzaron a envolver pequeños objetos como una revista con la portada de una fotografía de Marilyn Monroe en la portada y empaquetada en papel transparente. El resto de la historia la conocemos, grandes empaquetamientos de objetos, de edificios y de islas. Influenciados por el dadaísmo y recordando la obra el Enigma de Isidore Ducasse de Man Ray, proponen embalar la Escuela Militar de París, aunque finalmente tiene que conformarse con una intervención en una calle pequeña que cierran y bloquean con una cortina de hierro a base de bidones. Sus primeras intervenciones envolviendo los escaparates de las tiendas de la ciudad fueron poco a poco sufragando proyectos más grandes. En sus obras efímeras, la posterior venta de los proyectos es lo que sufraga posteriores intervenciones. Durante dos semanas en el verano de 1995 envolvieron el edificio del Reichstag de Berlín, históricamente la sede del Parlamento alemán.

Helena Almeida en la década de los años setenta comenzó a fusionar disciplinas y lenguajes artísticos como la fotografía, la pintura, el dibujo y la performance. Su cuerpo pasa a ocupar el espacio. Sus Pinturas habitadas (1975) son ilusiones espejo donde la artista comienza a cubrir la imagen de su cara con pintura azul hasta que hace que desaparezca. Esta pintura azul (que tendría relación con el International Klein Blue) es un artificio, un obstáculo, una estrategia para desaparecer de las mismas. Sus fotografías pintadas son juegos de representación con dos momentos diferentes, el pasado (la fotografía) y el después (los elementos adicionales).

El artista Maurizzio Cattelan explora el sufrimiento, la infelicidad y la insatisfacción que parece ser parte de la vida contemporánea. En All, una serie de esculturas que simulan cadáveres tapados, se ocupa de la masacre, la persecución y el martirio que se repiten a lo largo de la historia humana. Nos invita a reflexionar acerca de la violencia, que se ha convertido en una característica de nuestra sociedad, y como ésta puede lograr que mañana nos convirtamos en uno de esos cadáveres anónimos. El tapar y ocultar la identidad de las víctimas a través del anonimato esculpa al espectador de todo el horror de la muerte, pero al mismo tiempo, amplifica enormemente las incógnitas sobre el origen de esta cruda brutalidad. Podríamos estar ante un acto de genocidio, ante las secuelas de una batalla o un desastre natural, una plaga devastadora, un atentado suicida o ante las víctimas de la mafia siciliana. Todas ellas causas de sufrimiento y que el artista presenta con una gran economía de medios a través del tapado. En cualquiera de las ubicaciones en las que la obra se presenta, el espacio se convierte en una cámara funeraria, en una zona frontera inquietante entre el anonimato y la muerte.

Klara Lidén (Noruega, 1979) reflexiona sobre la alineación de la ciudad. En sus series Painting Póster (2007), (Pinturas póster), para criticar la omnipresencia de la publicidad en el espacio público ha utilizado una masa de carteles de la calle, los ha pegado y a continuación, los ha tapado con un papel blanco haciendo que desapareciera toda el sentido que podría haber tenido en este medio. La obra final es un conjunto de imágenes pictóricas montadas sobre la pared, hechas de capas y capas de carteles pegados unos encima de otros bloqueando la imagen superior con un rectángulo blanco.

Finalmente, Fayçal Baghriche en Family Friendly (2012) trabaja con una serie de imágenes de revistas que el artista compró en Dubai y que habían sido censuradas con marcas negras. Las imágenes tomadas de las revistas eran de obras de arte famosas donde aparecían desnudos. Este es un género propiamente del arte occidental, si borraramos el desnudo de la historia del arte occidental no quedará mucho. $Y$ es que en la cultura musulmana no hay desnudos en el arte y es raro incluso representar el cuerpo. Es una cuestión de privacidad y de los límites entre lo público y lo privado. En oriente, en las revistas se reconocen a las mujeres por sus caras, su cuerpo no se muestra. Es la abstracción de la imagen. Una forma respetuosa y sutil de esconder las imágenes porque el estado de la imagen cambia cuando se censura. Sus trabajos son como obras invisibles porque en realidad a través del tapado no las vemos del todo. 


\section{Conclusiones.}

Todos estos ejemplos nos permiten afirmar que las estrategias presentes en David Hammons y en estos otros artistas logran mantener expectante la mirada del visitante de forma que más allá de su antivisualidad sus obras en realidad logran que nos detengamos y pensemos más allá de lo que se muestra. Son poéticas de la negación de lo visual como "aquellas estrategias que abordan las formas de distanciamiento, interposición, retardo y ocultación de una representación de la realidad" (Meana Martínez, 2011).

\section{FUENTES REFERENCIALES.}

Ferrer, Juan E., Simbolismo mágico de los espejos Revista Digital Nueva Acrópolis. http://www.nueva-acropolis.es/es/cultura/319simbolismo/14406-simbolismo-magico-de-los-espejos [Consult. 10.01.2017]

Galder Reguera. (2008). La cara oculta de la luna. Ed. Infraleves. ISBN:978-84-96898-27-1

Hernández-Navarro, (2006). La so(m)bra de lo real: El arte como vomitorio. Colleció Novatores. ISBN: 84-7822-467-X

Meana Martínez, Juan Carlos, (2011) Poéticas de la negación de lo visual. ISBN: 978-989-8300-14-0 